\title{
MODELS FOR PREDICTION OF GLOBAL SOLAR RADIATION ON HORIZONTAL SURFACE FOR AKURE, NIGERIA
}

\author{
OLUMIDE OLUFEMI AKINNAWO, JAMES SAMUEL OLADUNJOYE OLUDOTUN, ABEL GIWA USIFO AND \\ SAMUEL OLUYEMI ADEJUWON
}

(Received 06 May 2016; Revision Accepted 27 June 2016)

\begin{abstract}
The estimation of global solar radiation continues to play a fundamental role in solar engineering systems and applications. This paper compares various models for estimating the average monthly global solar radiation on horizontal surface for Akure, Nigeria, using solar radiation and sunshine duration data covering years 1981 to 1995. The analysis was performed using Angstrom models, two dimensional principal component analysis (PCA) and adaptive neuro-fuzzy inference system (ANFIS). The performance of the models were tested using statistical indicators such as mean bias error (MBE), mean percentage error (MPE), root mean square error (RMSE) and correlation coefficient (CC). The results indicated that ANFIS and linear regression analysis provide relatively higher degree of prediction, with the performance of ANFIS slightly better.
\end{abstract}

KEYWORDS: Angstrom model, fuzzy logic system, principal component analysis, regression analysis, solar radiation, sunshine duration.

\section{INTRODUCTION}

Global solar radiation (GSR) measurements play a fundamental role in the design of solar engineering projects and in evaluation of system performance. Nigeria is currently focusing on solar energy for power generation especially in remote villages that are not yet connected to the grid system to make electricity available to rural dwellers. The data for the average solar radiation are not readily available for many locations due to a number of factors among which are cost and maintenance of the measuring equipment (Paltineanu et al. 2002; Muzathik et al. 2011). The alternative approach to obtaining the measurement is to correlate it with other meteorological parameters such as temperature, sunshine duration, relative humidity, etc., measured at the study location (Fagbenle 1990; Falayi and Rabiu 2005). The most commonly used parameter for this estimation by many researchers however, is the sunshine duration (Akpabio and Etuk 2003; El-Sebaii and Trabea 2005). The models derived from these parameters may then be used to estimate the global solar radiation values for places where the data are not available having similar geographical features.

Angstrom (1924) proposed the first linear regression model for estimating global solar radiation using sunshine duration data. The model was later modified by Prescott (1940) by comparing the clearness index, ${ }^{H} / H_{o}$ to the relative sunshine index, $n / N$ which gives information about the atmospheric condition of the study area. The equation is defined in (1):

$$
H / H_{o}=a+b(n / N)
$$

The clearness index is the ratio of the solar radiation at the Earth surface $(H)$ to extraterrestrial radiation $\left(H_{0}\right)$, while the relative sunshine index or cloudless index is the ratio of the actual sunshine hour (n) to the monthly average daily maximum number of hours of possible sunshine $(\mathrm{N})$. The empirical constants $a$ and $b$ have been shown to have seasonal and latitudinal variability (Srivastava and Pandey, 2013). On a cloudless day the relative sunshine duration is unity, and thus the clearness index is equal to $(a+b)$. On a cloudy day however, the value of the clearness index is equal to $a$.

Sen (2008) carried out a comprehensive review on linear and non-linear energy models for estimation of GSR on horizontal surfaces using single predictor variable. Among these models are the principal component analysis (PCA) and fuzzy logic system.

The present study aims to determine model coefficients using the Angstrom-Prescott formula through regression analysis, two-dimensional PCA and adaptive neuro-fuzzy inference system (ANFIS) for estimating GSR on horizontal surface. Statistical

Olumide Olufemi Akinnawo, Department of Physical and Earth Sciences, Crawford University, Igbesa, Ogun State, Nigeria.

James Samuel Oladunjoye Oludotun, Department of Physical and Earth Sciences, Crawford University, Igbesa, Ogun State, Nigeria.

Abel Giwa Usifo, Department of Physical and Earth Sciences, Crawford University, Igbesa, Ogun State, Nigeria. Samuel Oluyemi Adejuwon, Department of Mechanical Engineering, Polytechnic of Ibadan, Oyo State, Nigeria. 
44 OLUMide olufemi aKinNawo, James samuel oladunjoye oludotun, abel giwa usifo and SAMUEL OLUYEMI ADEJUWON

analysis will then be used to compare the estimated monthly average GSR with the measured value.

\section{Data and methods of estimation}

Data used in this analysis is obtained from the Nigerian Meteorological Agency (NIMET), Lagos, for Akure $\left(7.25^{\circ} \mathrm{N}, 5.20^{\circ} \mathrm{E}\right)$, a tropical location. The mean monthly values of sunshine duration and GSR for a period of fifteen years (1981 - 1995) were used.

In order to use the Angstrom-type formula, the average monthly global solar radiation, obtained using Gun-Bellani radiometer measured in $\mathrm{ml}$ had to be converted to $M J \mathrm{~m}^{-2}$ using the conversion factor of $1.357 \pm 0.176$ (Folayan, 1988). The extraterrestrial radiation, $H_{0}$ and the monthly average daily maximum number of hours of possible sunshine, $N$ were determined (Iqbal, 1986) as in (2):

$H_{0}=\frac{24}{\pi} G_{0}\left(\cos \phi \cos \delta \sin w_{0}+\frac{\pi}{180} w_{0} \sin \phi \sin \delta\right) \cdots(2)$

and $\boldsymbol{N}=\left(\frac{2}{15}\right) \boldsymbol{w}$ where,

$G_{0}=1367\left(1+0.033 \cos \left(\frac{360 N_{d}}{365}\right)\right)$

$\delta=23.45 \sin \left(\frac{360\left(284+N_{d}\right)}{365}\right)$

$w$ is the sunset hour given as:

$w=\cos ^{-1}(-\tan \phi \tan \delta)$

$N_{d}=$ Julian day number, $\Phi=$ Latitude,

$\delta=$ declination angle.

The paper considers three different approaches. The first approach uses the AngstromPrescott formula for first, second and third-order regression models. The model coefficients of the first order Angstrom-Prescott formula type equation were obtained using linear regression analysis. The scatterplot for the clearness index versus relative sunshine index for the station is obtained for all the months in a period of 15 years, between 1981 and 1995 and the model coefficients determined. The second and third order equations were evaluated using the MATLAB intrinsic function nlintool (Hejase and Assi,2011). The form of the three different models is as shown in Table 1. For the models, $b, x$ and $y$ represent the model coefficients, sunshine duration index and clearness index respectively.

Table 1: Angstrom-Prescott type models

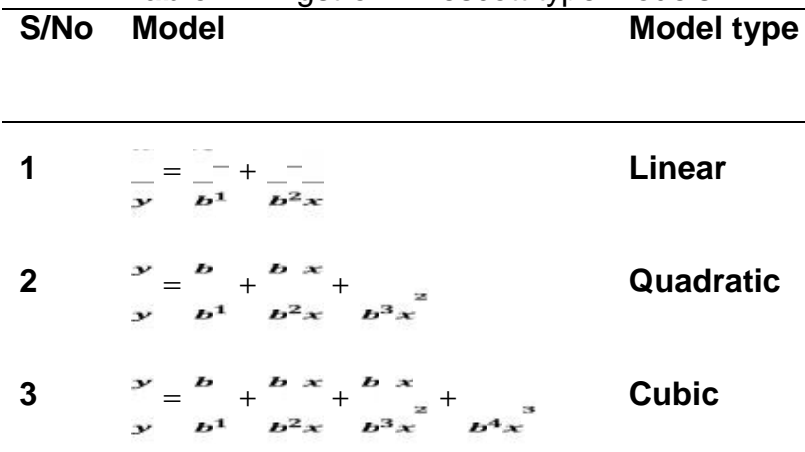

The second approach uses two-dimensional PCA to construct orthogonal-mutually uncorrelated principal components. The method employs centralization of the data by removing the average value from each variable such that the new data set produce azero mean. The covariance matrix was then obtained from the two variables of the newly reconstructed data set. Finally, the eigenvalues and eigenvectors of the covariance matrix were obtained. The eigenvectors corresponding to the biggest eigenvalues (maximum variance in the data) were used to fit a straight line to the original data set. The straight line is the major principal axis corresponding to the first principal component. The other smaller eigenvalues give the minimum variance in the data and correspond to the second principal component. The covariance for the $\mathrm{x}$ and $y$ data is defined as:
$\operatorname{Cov}(x, x)=\frac{\sum_{i=1}^{n}\left(x_{i}-\bar{x}\right)\left(x_{i}-\bar{x}\right)}{(n-1)}$

$\operatorname{Cov}(x, y)=\frac{\sum_{i=1}^{n}\left(x_{i}-\bar{x}\right)\left(y_{i}-\bar{y}\right)}{(n-1)}$

and the covariance matrix $[\mathrm{S}]$ is defined as:

$[S]=\left(\begin{array}{ll}\operatorname{Cov}(x, x) & \operatorname{Cov}(x, y) \\ \operatorname{Cov}(y, x) & \operatorname{Cov}(y, y)\end{array}\right)$

where the leading diagonal corresponds to the individual variances of the $x$ and the $y$ data and the other gives their joint variance (Wilks, 2011). The PCA model is defined in (10): 


$$
y_{\text {pca }}=b_{1}+b_{2} x
$$

where, $b, \quad x$ and $y_{p c a}$ represent the PCA model parameters, sunshine duration index and clearness index respectively.

The final approach uses ANFIS in the estimation of GSR for Akure. ANFIS is a class of adaptive multilayer network that combines the learning ability of artificial neural network and fuzzy logic principles. The Sugeno style inference system of the Matlab $^{\odot}$ toolbox was used in the study. This system uses a single spike for representing the membership function of the rule consequent and a weighted average techniques for its defuzzification (Demicco and Klir, 2003).

Statistical analyses were performed on the estimated and measured values using parameters like mean bias error (MBE), root mean square error (RMSE), Mean Percentage Error (MPE) and correlation coefficient (CC):

$M B I=\sum_{i=1}^{n} \frac{\left(H_{c a l}-H_{o b s}\right)}{n}$

$R M S E=\left\{\frac{\sum_{i=1}^{n}\left(H_{c a l}-H_{o b s}\right)}{n}\right\}^{1 / 2}$
$M P I=\frac{1}{n} \sum_{i=1}^{n}\left(\frac{H_{o b s}-H_{c a l}}{H_{o b s}}\right) 100$

$$
C C=\frac{\sum_{i=1}^{n}\left(H_{c a l}{ }^{-} \bar{H}_{c a l}\right)\left(H_{o b s}-\bar{H}_{o b s}\right)}{\left\{\left[\sum_{i=1}^{n}\left(H_{c a l}-\bar{H}_{c a l}\right)^{2}\right]\left[\sum_{i=1}^{n}\left(H_{o b s}-\bar{H}_{o b s}\right)^{2}\right]\right\}^{1 / 2}}
$$

where, $H_{c a l}$ and $H_{o b s}$ stand for the predicted and measured values respectively, and $n$ is the total number of observations. The RMSE is always positive and has ideal value equal to zero while the ideal values for the MBE and correlation coefficient should be zero and one respectively (Iqbal, 1986).

\section{RESULTS AND DISCUSSION}

The correlation between the clearness index and the relative sunshine index for Akure using mean monthly values are shown in Fig. 1-3. Fig. 1, represents the scatterplot obtained by using both the first order linear regression method and the two-dimensional PCA.The regression method deals with averaging without a consideration of variability within the data while the PCA considers both averaging and variability of the data set (Sen, 2008). From Fig. 1, we obtained the least square regression equation as:

$$
H / H_{o}=0.1981+0.5182(n / N)
$$

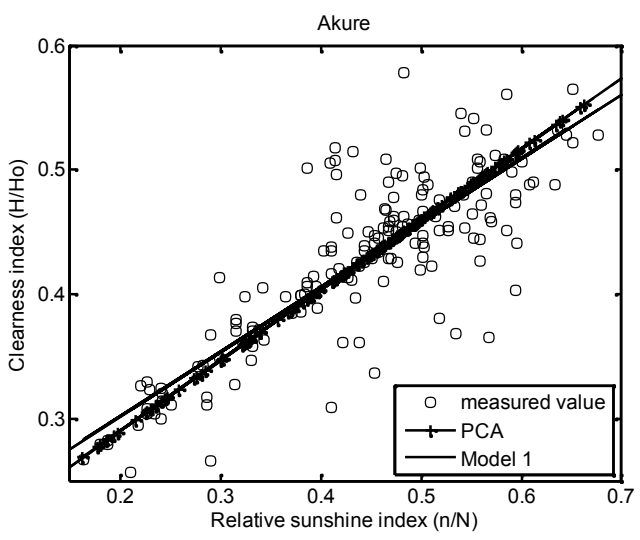

Fig. 1: Correlation between $\mathrm{H} / \mathrm{Ho}$ and $\mathrm{n} / \mathrm{N}$ for Akure using mean monthly values.

The model constants obtained from Eq. (15) found $a$ to be 0.1981 and $b$ to be 0.5182 . So, the transmissivity of the atmosphere, translate to the clearness index on a cloudless day and was found to be 0.7163 . This value lies between $0.68-0.75$ as indicated by many researchers for a humid tropical climate (Akpabio and Etuk, 2003; Muzathik et. al, 2011). Also, from the figure, the PCA, yields the linear equation:

$$
H_{p c a} / H_{o}=0.1768+0.5667(n / N)
$$

The model constants obtained from Eq. (16) found $a$ to be 0.1768 and a high value for $b$ to be 0.5667 . In this case, the clearness index for a cloudless day yields 0.7435 .

Figures 2 and 3 show the second and third orders Angstrom-Prescott type models respectively. The regression equations for these were:

$$
H / H_{o}=0.1280+0.8307(n / N)-0.3862(n / N)^{2}---
$$


46 OLUMIDE OLUFEMI AKINNAWO, JAMES SAMUEL OLADUNJOYE OLUDOTUN, ABEL GIWA USIFO AND SAMUEL OLUYEMI ADEJUWON

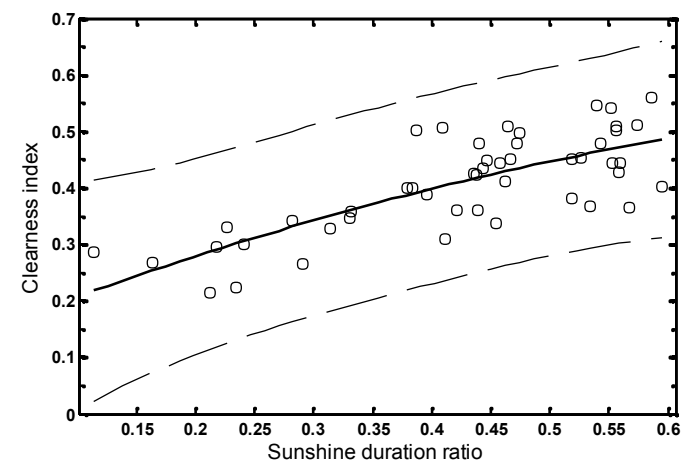

Fig. 2: Regression model with quadratic function between clearness index and sunshine duration ratio

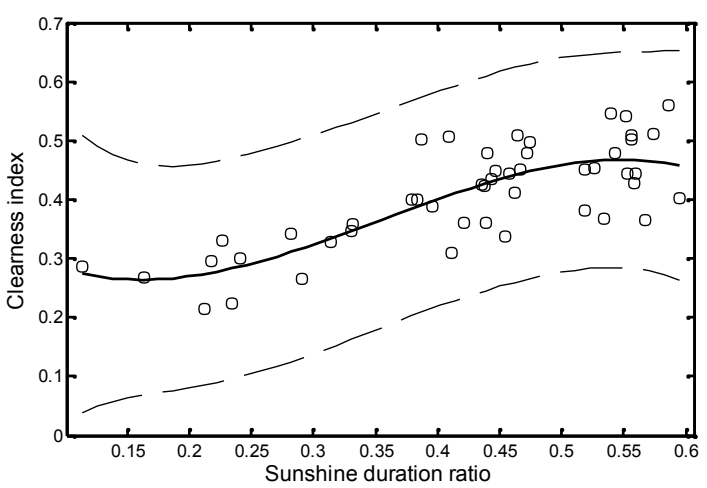

Fig. 3: Regression model with cubic function between clearness index and sunshine duration ratio

$H / H_{o}=0.3987-1.8543(n / N)+7.4482(n / N)^{2}-7.0005(n / N)^{3}$

Figures 4 and 5show the plots for the variation of the measured, against the predicted GSRs obtained from all the models for 1982 and 1983 respectively. These figures show two minima with the first minimum occurring between February and March and the more enhanced second minimum occurring at August. Also from the figure, there exists corresponding two maxima with the first maximum occurring between January and February and the second maximum occurring at November. This phenomenon for Nigeria has been reported by other researchers (Akpabio and Etuk, 2003).

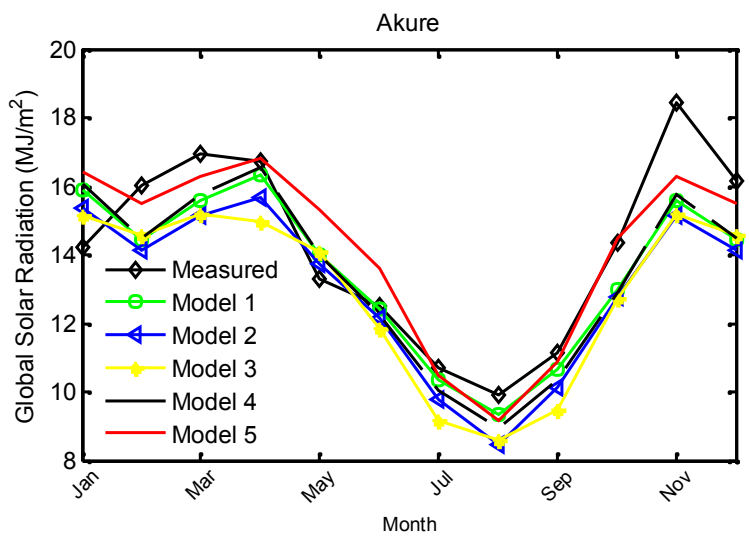

Fig. 4: Comparison of GSR for 1982 in Akure 


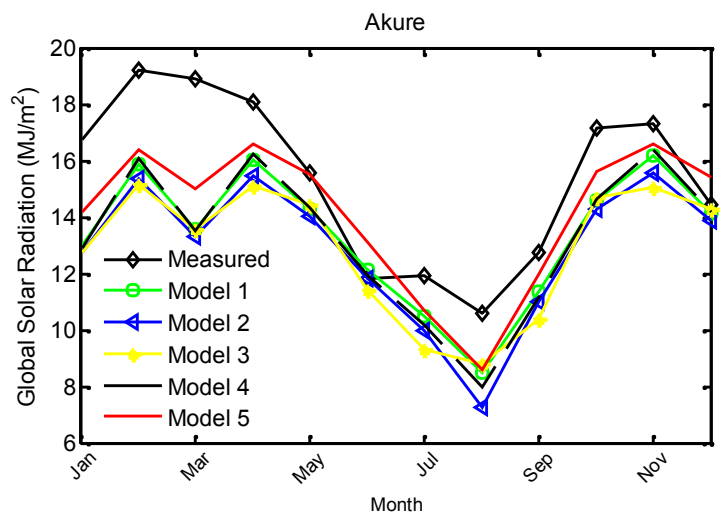

Fig. 5: Comparison of GSR for 1983 in Akure

The values obtained from the regression models, PCA and Fuzzy inference system on the horizontal surface are given in Tables 2 and 3 for 1982 and 1983 respectively. Also the comparisons of the GSR measured values for the years are given in Tables 4 and 5 respectively. The calculated PE, MPE, MBE, RMSE and $\mathrm{CC}$ are shown at the bottom of the tables.

Table 2: Values of Sunshine duration and GSRs for year 1982

\begin{tabular}{|c|c|c|c|c|c|c|c|}
\hline Months & $\begin{array}{l}\text { Sunshine } \\
\text { Duration } \\
\text { (Hour) }\end{array}$ & $\begin{array}{l}\text { GSR measured } \\
\left(M^{-2} m^{-2} d^{-1}\right)\end{array}$ & $\begin{array}{l}\text { GSR } \\
\text { Model } 1 \\
(\text { Eq. 15) } \\
\left(\begin{array}{ll}M^{-} m^{-} \\
\left.\text {day }^{-1}\right)\end{array}\right.\end{array}$ & $\begin{array}{l}\text { GSR } \\
\text { Model } 2 \\
(\text { Eq. 16) } \\
\left(\text { MJ }^{-} \mathrm{m}^{-}\right.\end{array}$ & $\begin{array}{l}\text { GSR } \\
\text { Model } 3 \\
(\text { Eq. 17) } \\
\left(M J{ }^{-1} m^{-}\right. \\
\left.{ }^{2} \text { day }^{-1}\right)\end{array}$ & $\begin{array}{l}\text { GSR } \\
\text { Model } 4 \\
(\text { Eq. 18) } \\
\left(M^{-1} m^{-}\right. \\
\left.{ }^{2} \text { day }^{-1}\right)\end{array}$ & $\begin{array}{l}\text { GSR } \\
\text { Model } 5 \\
\text { ANFIS } \\
\left(M^{2} \text { day }^{-1}\right)\end{array}$ \\
\hline January & 6.5 & 14.22 & 15.885 & 15.354 & 15.162 & 16.077 & 16.4 \\
\hline February & 5.5 & 16.04 & 14.431 & 14.146 & 14.559 & 14.488 & 15.5 \\
\hline March & 6.3 & 16.95 & 15.594 & 15.128 & 15.181 & 15.759 & 16.3 \\
\hline April & 6.8 & 16.723 & 16.321 & 15.68 & 14.974 & 16.554 & 16.8 \\
\hline May & 5.2 & 13.31 & 13.995 & 13.747 & 14.1 & 14.011 & 15.3 \\
\hline June & 4.1 & 12.514 & 12.396 & 12.141 & 11.861 & 12.262 & 13.6 \\
\hline July & 2.7 & 10.693 & 10.362 & 9.769 & 9.18 & 10.037 & 10.5 \\
\hline August & 2 & 9.897 & 9.344 & 8.446 & 8.597 & 8.925 & 9.15 \\
\hline September & 2.9 & 11.148 & 10.652 & 10.13 & 9.47 & 10.355 & 10.9 \\
\hline October & 4.5 & 14.334 & 12.978 & 12.751 & 12.736 & 12.898 & 14.5 \\
\hline November & 6.3 & 18.429 & 15.594 & 15.128 & 15.181 & 15.759 & 16.3 \\
\hline December & 5.5 & 16.154 & 14.431 & 14.146 & 14.559 & 14.488 & 15.5 \\
\hline
\end{tabular}


48 OLUMIDE OLUFEMI AKINNAWO, JAMES SAMUEL OLADUNJOYE OLUDOTUN, ABEL GIWA USIFO AND SAMUEL OLUYEMI ADEJUWON

Table 3: Values of Sunshine duration and GSRs for year 1983

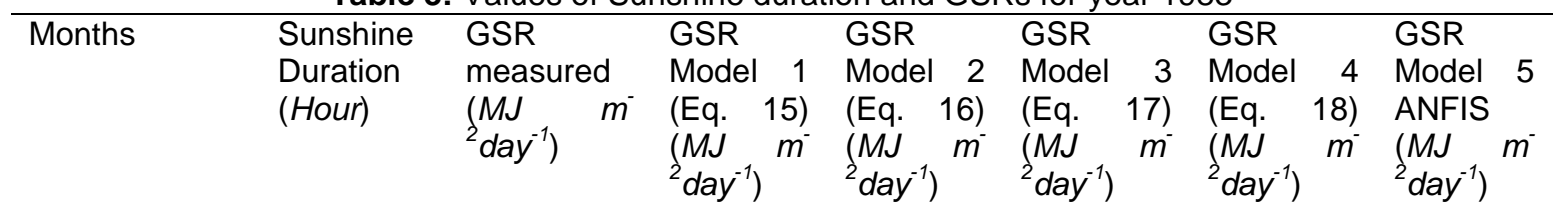

\begin{tabular}{lrrrrrrr}
\hline January & 4.5 & 16.723 & 12.978 & 12.751 & 12.736 & 12.898 & 14.2 \\
February & 6.5 & 19.225 & 15.885 & 15.354 & 15.162 & 16.077 & 16.4 \\
March & 4.9 & 18.884 & 13.559 & 13.332 & 13.555 & 13.534 & 15 \\
April & 6.6 & 18.088 & 16.03 & 15.465 & 15.122 & 16.236 & 16.6 \\
May & 5.4 & 15.585 & 14.286 & 14.015 & 14.417 & 14.329 & 15.5 \\
June & 3.9 & 11.831 & 12.106 & 11.825 & 11.421 & 11.945 & 13.1 \\
July & 2.8 & 11.945 & 10.507 & 9.951 & 9.319 & 10.196 & 10.7 \\
August & 1.4 & 10.58 & 8.472 & 7.238 & 8.809 & 7.971 & 8.6 \\
September & 3.4 & 12.741 & 11.379 & 11.001 & 10.368 & 11.15 & 12 \\
October & 5.6 & 17.178 & 14.577 & 14.276 & 14.689 & 14.647 & 15.6 \\
November & 6.7 & 17.292 & 16.175 & 15.574 & 15.059 & 16.395 & 16.6 \\
December & 5.3 & 14.448 & 14.141 & 13.882 & 14.264 & 14.17 & 15.4 \\
\hline
\end{tabular}

From Table 4, the calculated CC are strongly correlated and approximately equal to each other. Consequently we rely on the RSME values which give better results of 1.164 for the ANFIS model, 1.334 for the model 1 and 1.349 for the PCA model. The MPE gives better results for the ANFIS model and the model 1. The same trend is observed for the values in Table 5, hence, the models that give better performance for the estimation of GSR at the study site were the ANFIS, the linear and the PCA models respectively in that order.

Table 4: Values of calculated PE, MPE, MBE RMSE and CC for year 1982

\begin{tabular}{lrrrrr}
\hline & \multicolumn{5}{c}{ PE } \\
\cline { 2 - 6 } Months & Model 1 & Model 2 & Model 3 & Model 4 & \multicolumn{1}{c}{ ANFIS } \\
\hline January & -11.707 & -7.978 & -6.627 & -13.060 & -15.331 \\
February & 10.030 & 11.807 & 9.234 & 9.679 & 3.368 \\
March & 8.001 & 10.752 & 10.436 & 7.027 & 3.836 \\
April & 2.404 & 6.233 & 10.456 & 1.009 & -0.462 \\
May & -5.149 & -3.287 & -5.938 & -5.266 & -14.952 \\
June & 0.936 & 2.978 & 5.213 & 2.007 & -8.682 \\
July & 3.104 & 8.645 & 14.157 & 6.136 & 1.809 \\
August & 5.587 & 14.665 & 13.134 & 9.826 & 7.549 \\
September & 4.451 & 9.133 & 15.052 & 7.116 & 2.229 \\
October & 9.460 & 11.040 & 11.149 & 10.015 & -1.160 \\
November & 15.384 & 17.914 & 17.623 & 14.488 & 11.553 \\
December & 10.664 & 12.428 & 9.873 & 10.315 & 4.048 \\
\hline MPE & 4.430 & 7.861 & 8.647 & 4.941 & -0.516 \\
MBE & -0.702 & -1.154 & -1.238 & -0.733 & 0.028 \\
RMSE & 1.334 & 1.608 & 1.652 & 1.349 & 1.164 \\
CC & 0.903 & 0.905 & 0.909 & 0.903 & 0.898 \\
\hline
\end{tabular}


Table 5: Values of calculated PE, MPE, MBE RMSE and CC for year 1983

\begin{tabular}{lrrrrr}
\hline & \multicolumn{5}{c}{ PE } \\
\cline { 2 - 6 } Months & Model 1 & Model 2 & Model 3 & Model 4 & Model 5 \\
\hline January & 22.394 & 23.749 & 23.842 & 22.870 & 15.086 \\
February & 17.377 & 20.135 & 21.134 & 16.376 & 14.696 \\
March & 28.198 & 29.402 & 28.219 & 28.331 & 20.568 \\
April & 11.377 & 14.501 & 16.398 & 10.238 & 8.226 \\
May & 8.336 & 10.073 & 7.494 & 8.062 & 0.546 \\
June & -2.322 & 0.055 & 3.466 & -0.960 & -10.726 \\
July & 12.038 & 16.695 & 21.981 & 14.639 & 10.421 \\
August & 19.921 & 31.582 & 16.741 & 24.658 & 18.712 \\
September & 10.691 & 13.659 & 18.626 & 12.489 & 5.817 \\
October & 15.143 & 16.895 & 14.490 & 14.735 & 9.185 \\
November & 6.455 & 9.935 & 12.909 & 5.185 & 3.999 \\
December & 2.125 & 3.912 & 1.271 & 1.922 & -6.593 \\
\hline MPE & 12.644 & 15.883 & 15.548 & 13.212 & 7.495 \\
MBE & -2.035 & -2.488 & -2.467 & -2.081 & -1.235 \\
RMSE & 2.517 & 2.898 & 2.858 & 2.547 & 1.896 \\
CC & 0.858 & 0.855 & 0.868 & 0.858 & 0.865 \\
\hline
\end{tabular}

\section{CONCLUSION}

In this study, the regression equations, that is, first order, second order and third order AngstromPrescott formula have been used for the estimation of global solar radiation in Akure. The two-dimensional PCA and fuzzy interference system were also considered for the GSR estimation. The statistical tests carried out on the predicted results show that the fuzzy inference system is slightly more efficient than the linear regression model and relatively far better than other methods in terms of performance. Consequently, the fuzzy inference system and linear regression model are suitable for GSR estimation for Akure and its environ.

\section{REFERENCES}

Akpabio, L. E and Etuk, S. E., 2003. Relationship between global solar radiation and sunshine duration for Onne, Nigeria. Turkish Journal of Physics, 27, (2): 161-167.

Angstrom, A., 1924. Solar and terrestrial radiation. Quarterly Journal of the Royal Meteorological Society 50, (210): 121-126.

Demicco, R. V and Klir, G. J., 2003. Fuzzy logic in geology, pp 80-93. Academic Press.

El-Sebaii, A. A and Trabea, A. A., 2005. Estimation of global solar radiation on horizontal surface over Egypt. Egypt journal solids 28, (1): 163-175.

Fagbenle, R. L., 1990. Estimation of the total radiation in Nigeria using meteorological data. Nigerian journal of renewable energy (1): 1-10.
Falayi, E. O and Rabiu, A. B., 2008. Prediction of the clearness index for some Nigeria station using temperature data. Journal of science and technology 28, (2): 94-101.

Folayan, C. O., 1988. Estimate of global solar radiation bound for some Nigerian cities. Nigerian Journal of Solar Energy, 7, 36-48.

Hejase, H. A. N and Assi, A. H., 2011. MATLABAssisted regression modelling of mean daily global solar radiation in Al-Ain, UAE. INTECH Open Access Publisher.

lqbal, M., 1986. An introduction to solar radiation, Academic press Toronto, 215-234.

Muzathik, A. M., Nik, W. B. W., Ibrahim, M. Z., Samo, K. B., Sopian, K and Alghoul, M. A., 2011. Daily global solar radiation estimation base on sunshine hour, Journal of thermal science and technology, (1): 75-80.

Paltineanu, C., Mihailescu, I. F., Torica, V and Albu, A. N., 2002. Correlation between sunshine and global solar radiation in South-Eastern Romania. A of agrophysics, polish academy of science 16, (1): 139-145.

Prescott, J. A., 1940. Evaporation from a water surface in relation to solar radiation. Transaction of the royal society of South Australia, 64, (1): 114118.

Srivastava, R. C and Pandey, H., 2013. Estimating Angstrom-Prescott coefficients for India and developing correlation between sunshine hours 
50 OLUMIDE OLUFEMI AKINNAWO, JAMES SAMUEL OLADUNJOYE OLUDOTUN, ABEL GIWA USIFO AND SAMUEL OLUYEMI ADEJUWON

and global solar radiation for India, ISRN Renewable Energy 1(1).

Sen, Z., 2008. Solar energy fundamentals and modeling techniques: atmosphere, environment, climate change and renewable energy. Springer Science and Business Media.
Wilks, D. S., 2011. Statistical methods in the atmospheric sciences, pp 528-555. Academic press. 